\title{
Uf
}

\section{POR QUAL CAMINHO DEVEMOS IR? UMA LEITURA DE THE ROAD, DE CORMAC MCCARTHY}

Alysson Tadeu Alves de Oliveira (USP)

Recebido em 02 set 2016. Mestre em Letras pela USP, doutorando em Letras. Aprovado em 07 out 2016. Autor do ensaio "O Espectro do Capitalismo: uma leitura de Cosmópolis", publicado na Revista Orson. Membro do grupo Sequências Brasileiras. Interessado nas áreas de Estudos de Cultura, Literatura de Língua Inglesa Contemporânea e Ficção-Científica. Lates: http://buscatextual.cnpq.br/buscatextual/visualizacv. do?id=K4000246A7. Contato: aly.oliveira@usp.br.

Resumo: Publicado em 2006, o romance The Road, de Cormac McCarthy, é uma narrativa apocalíptica, na qual dois personagens, pai e filho, atravessam um país desolado em busca de melhores condições de vida perto do mar. Esse artigo faz uma análise da obra a partir de conceitos formulados pelo crítico norte-americano Fredric Jameson de mapeamento cognitivo, utopia/ distopia. Dessa forma relaciona a narrativa não apenas com o cenário dos EUA pós-11 de setembro, como também com a crise do capitalismo do século XXI.

Palavras-chave: Cormac McCarthy; Fredric Jameson; 11 de Setembro; Mapeamento cognitivo: Literatura Contemporânea.

Abstract: Published in 2006, Cormac McCarthy's novel The Road is an apocalyptic narrative, in which a pair of 
characters, father and son, cross a desolated country searching for better life conditions nearby the sea. This article brings a reading of the book from concepts formulated by North American critic Fredric Jameson such as cognitive mapping and utopia/dystopia. Not only is the narrative related to September 11's USA, but also with the crises of 21st century's capitalism. Keywords: Cormac McCarthy; Fredric Jameson; 9/11; Cognitive Mapping; Contemporary Literature.

Most people who survive devastating disaster want the opposite of a clean slate: they want savage whatever they can and begin repairing what was not destroyed; they want to reaffirm they relatedness to the place that formed them.

(Naomi Klein, The Shock Doctrine)

Where I am, I don't know, I'll never know, in the silence you don't know you must go on,

I can't go on, I'll go on.

(Samuel Beckett, The Unnamable)

Mapas são os instrumentos usados pelo o homem para se localizar no espaço. A certa altura, no romance The Road (2006), de Cormac McCarthy, um dos protagonistas, um garoto, olha em um mapa para tentar entender onde ele e o pai estão, e por qual caminho devem seguir para chegar ao seu destino. "O menino fez que sim. Ficou sentado olhando para o mapa [...] tudo em seu lugar. Justificado no mundo" (MCCARTHY, 2006, p.182)․․ A terceira frase "tudo no seu lugar", no entanto, é mera ironia, pois, pai e filho atravessam um mundo desolado, pós-apocalíptico, em busca de refúgio onde acreditam que a vida poderá ser melhor.

1 Todas as citações, quando não informada edição brasileira, foram traduzidas por mim. 
Mapas, explica Fredric Jameson, podem ser instrumentos para nos localizar não apenas no espaço, mas também no tempo, e, a partir daí, entendermos quem somos e o mundo que nos cerca. A isso, ele chama de Mapeamento Cognitivo (Cognitive Mapping): "a extrapolação da [...] análise espacial para o campo da estrutura social, ou seja, no nosso momento histórico" (JAMESON, 2000, p.283). Essa espécie de mapeamento talvez fosse mais útil ao garoto do romance do que apenas um geográfico apontando caminhos.

E a partir do conceito descrito por Jameson, pretendo aqui fazer um mapeamento cognitivo do romance, situando a narrativa no tempo e espaço, para, enfim, localizar quem são esses dois protagonistas, e como se relacionam com o mundo em que vivem. Jameson contribui para essa discussão também com suas formulações sobre utopia/distopia e ficção-científica, enquanto os conceitos como already dead e new chronical, formulados pelo crítico cultural Eric Cazdyn, ajudam-nos a compreender um pouco sobre o perfil dos personagens do romance.

Ao propor a localização da trama nos Estados Unidos contemporâneo - o livro é de 2006 - não podemos, é claro, deixar de lado o fantasma do 11 de Setembro, que paira, não apenas sobre o país, mas, sobre o mundo. Nesse sentido, é sintomático que o trauma apareça como um véu, que cai sobre os personagens, e o próprio romance seja incapaz de o figurar - explico mais sobre isso à frente. Alguns estudos dão conta exatamente da relação entre o trauma e os ataques de 2001, e, dessa forma, jogam uma luz sobre um dos aspectos mais intrigantes do livro: o que pode ter acontecido para destruir o mundo habitado pelos personagens do romance? 
The Road é o décimo romance de Cormac McCarthy - autor de livros como Blood meridian or The Evening Redness in the West (1985) e All the Pretty Horses (1992) - e lhe rendeu o Pulitzer na categoria em 2007. Nele, Pai e Filho - dois personagens sem nomes próprios, às vezes, também tratados como Homem e Garoto - atravessam um país desolado, rumo ao sul, onde esperam encontrar melhores condições climáticas e se estabelecerem. Ao longo do caminho, cruzam com diversas pessoas, como ladrões, uma gangue de canibais, e, um idoso, supostamente, o único personagem no romance a ter um nome, Ely. Os poucos pertences da dupla estão num carrinho de supermercado, que eles empurram laboriosamente.

Em um ensaio introdutório de uma coletânea crítica sobre o escritor, Stephen Frye compara McCarthy com Dante dizendo que para ambos "o mundo se apresenta como um tipo de purgatório no qual humanos lutam por um tempo com o esmagador senso de que a existência material encobre um mistério transcendente" (2013, p.7). Em The Road, o mundo inteiro é esse inferno dantesco, devastado e coberto de cinzas - "As cinzas do mundo finado carregadas pelos ventos sombrios e mundanos para lá e para cá no vazio" (2006, p.11) - os animais morreram, e aos poucos, o que sobrou, como algumas árvores e humanos, perecem:

O mundo encolhendo em torno de um centro cru e entidades partíveis. $\mathrm{O}$ nome das coisas lentamente seguindo essas coisas rumo a serem esquecidas. Cores. Os nomes dos pássaros. Coisas para comer. Finalmente, o nome das coisas que se acreditavam verdadeiras. Mais frágeis do que eles haviam pensado. O quanto já tinha sumido? (MCCARTHY, 2006, p.88-9) 
É curioso como, entretanto, jamais sabemos o que realmente aconteceu para deixar o mundo nesse estado. Alguns críticos (como o escritor William Kennedy, numa resenha elogiosa publicada no The New York Times) defendem que o cataclismo partiu de um acidente nuclear gerando aquilo a que vários deles se referem como um nuclear winter. Não há, porém, maneiras de precisar esta suposição. É, na verdade, mais fácil, a refutar, pois, um acidente nuclear traria consequências, como uma nuvem de radiação ou mutações, e nada parecido é mencionado no romance.

Outros críticos, no entanto, supõem um acidente natural, como um meteoro ou asteroide. Frye, num outro texto, alega que ambas suposições são plausíveis, e explica que o acidente atômico pode ser lido como "o resultado da maldade humana", enquanto o meteoro seria "resultado de um desastre da natureza e a capacidade destrutiva do universo (2009, p.169).

O próprio McCarthy, porém, confessou numa entrevista ao "The Wall Street Journal" que nunca imaginou o que possa ter acontecido, pois, para ele, interessam as consequências, não as causas:

Muitas pessoas me perguntam. Eu não tenho uma opinião. No Santa Fe Institute estou com cientistas de todas as disciplinas, e alguns deles geólogos disseram que parece um meteóro para eles. Mas pode ser qualquer coisa - atividade vulcânica ou poderia ser uma guerra atômica. Não é realmente importante. A questão é mesmo: o que você faria? (JURGENSEN, 2009)

O cataclismo inominado é aquilo que Louis Althusser e Étienne Balibar tratariam como uma causa ausente (2009 [1968], p.208209) - ausente porque já está dada no interior da própria estrutura. 
A análise de romance, no entanto, não é feita apenas daquilo que está nas páginas do livro. Investigá-lo é, também, analisar elementos que não são explícitos, e, ainda assim, necessários.

Uma leitura simbólica do acidente ausente da narrativa pode tomá-lo como uma figuração para os ataques terroristas de 11 de setembro de 2001. A impossibilidade de nomear reflete a dificuldade de compreender o que aconteceu. Em um ensaio sobre o trauma causado por esse momento, James Berger mostra que isso é um sinal da incapacidade, ao menos naquele momento, de figurar 0 acontecido:

"O que aconteceu? Como é chamado? 11 de setembro, 9/11, 911, os acontecimentos de 11 de setembro, o trauma de $11 / 9$, a catástrofe, a tragédia, o ataque, os ataques terroristas, o ataque à América, os horrores do 11 de setembro, os acontecimentos terríveis, o desastre, o terrorismo de 11 de setembro, os acontecimentos cataclísmicos, o ataque ao World Trade Center, acontecimentos recentes, as tragédias nacionais, os acontecimentos horríveis, acontecimentos apavorantes, crime em maciço.

[...] Não havia nada como chama-lo porque tomou o controle da realidade inteiramente. (BERGER, 2003, p.54)

Judith Greenberg vai além, e explica que:

O trauma do 11 de Setembro quebrou um escudo de proteção coletivo, e nem "todos os cavalos do rei e todos os homens" podem nos unir novamente, como éramos. Nosso sentido de lar precisa ser reconstruído de outra maneira, e ao fazer isso precisamos confrontar o que esses fragmentos significam para nós. Enquanto algumas memórias 
aparecem claras como o céu num dia claro de setembro, muitas partes de nossa experiência continuam faltando. [...] trauma está ligado a uma ideia de falta, algo que não pode ser compreendido. (2003, p.22)

É interessante notar como uma das frases desse trecho vai ao encontro do momento histórico-social em que vivemos, ao qual Jameson chama de Pós-Modernismo. Nele, somos incapazes de ver a totalidade, e lidamos com fragmentos. Para o teórico, essa crise na história, daí a fragmentação, nos deixa incapazes de figurar o passado e o futuro, vivemos, então, num presente eterno. Esse sujeito pós-moderno se materializa em The Road na figura do garoto, nascido depois do cataclismo, desconhecendo, portanto, o planeta antes de estar "tudo coberto com cinzas" (p.22), e sem a capacidade de imaginar o mundo futuro sem isso.

Berger, no entanto, afirma que a "catástrofe adquire um significado e valor como o primeiro capítulo de uma avaliação final" (2003, p.56). O romance norte-americano contemporâneo encontrou na crise da forma o ponto de partida, então, para tal avaliação. Na literatura do país, esse apuro é identificado como a perda da inocência e o ganho da experiência, e, todavia, muda conforme o momento histórico. Na narrativa nacional dos Estados Unidos, geralmente, está associada com a guerra (GRAY, 2011, p.2). Desde a luta pela independência, passando pela Guerra de Secessão e a do Vietnã, para chegar, finalmente, aos ataques de 2001.

Para Georg Lukács, o romance é a forma que expressa o estado de espírito do homem contemporâneo: 
O romance é a epopéia de uma era para a qual a totalidade extensiva da vida não é mais dada de modo evidente, para qual a imanência do sentido à vida tornou-se problemática, mas que ainda assim tem por intenção a totalidade. $(1971$, p.56)

É sintomático que McCarthy encontre no romance, então, o espaço para materializar o dilema do homem de nosso tempo, cuja existência está destruída por um trauma que ele (o homem contemporâneo) sequer pode nomear. Alguns autores, como Claire Messud (The Emperor's Children) e Don Delillo (Falling Man) investigam essa crise no plano familiar, domesticando-a (GRAY, 2011, p.40), enquanto McCarthy vai para o oposto do espectro, desfamiliarizando. Se a história precisa ser contada - mas não de forma direta, por conta do trauma ("algo que não pode ser compreendido", cf. Greenberg, acima) - a única maneira é aproximar-se do fato de forma indireta:

Ele traduz trauma numa narrativa de memória que captura como é viver depois da queda com exatitude, e ainda assim com a estranheza do simbolismo. Um símbolo, Carl Jung já sugeriu, é "a melhor expressão possível de uma realidade de um fato desconhecido". Se isso é assim, The Road é uma narrativa simbólica, uma história de algo poderosa, mas também movediça, algum trauma que resiste em ser contado. (GRAY, 2011, p.40)

Ao desfamiliarizar elementos no romance, McCarthy lida com aquilo que o próprio Jameson chama de Utopia que "pode servir o propósito negativo nos deixar mais cientes do nosso aprisionamento mental e ideológico" (2005, p.xiii). A ausência de poder institucionalizado ao longo de The Road ilustra como a Utopia 
"significa a libertação da hierarquia" (JAMESON, 2005, p.206), e, indo além, essa liberdade:

é definida como uma libertação da opressão e do próprio estado de poder, uma libertação que pode tomar a forma de pathos existencial, como com os dilemas do rebelde individual ou anti-herói, mas que agora após o fim do individualismo, parece tomar forma de grupos pequenos. (JAMESON, 2005, p.206)

Partindo dessas formulações, podemos concluir que o cataclismo do romance trouxe, entre outras coisas, a ruptura da estrutura sócio-política. Os laços humanos são poucos, quase inexistentes. E, mais uma vez, indiciam o mundo pós-moderno. Os protagonistas, Pai e Filho, nunca se aliam a outras pessoas que encontram na estrada. A mãe, que estava grávida quando da tragédia, sucumbiu pouco depois do nascimento do menino, abandonando-os e, supostamente, morrendo mais tarde. Não há menção de parentes ou mesmo amigos. Os únicos grupos organizados são os das pessoas que se transformam em canibais.

Para Paul Sheehan, essa é uma metáfora clara do fim da civilização, que acabou por descontinuar a exploração capitalista favorecendo os horrores e abominações do consumo capital (2012, p.95). O carrinho de compras, por sua vez, seria aquilo que Roberto Schwarz chama de "ideias fora do lugar". Num mundo destruído não há o que comprar, há a liberdade que acabou com a opressão, mas diante das circunstâncias, não há muito o que os personagens possam fazer com essa liberdade, a não ser, seguir a estrada.

Essa mesma estrada, aliás, é tanto física, como uma metáfora óbvia. Sheehan também aborda esse elemento, dizendo que "a 
estrada convoca um espaço estranhamente sinistro e de suspense, sugerindo uma pós-América ameaçadora, estranha" (2007, p.95). Ao mesmo tempo, é uma metonímia do capitalismo da modernidade, que floresceu nos EUA, entre as décadas de 1940 e 1960, com a indústria automotiva, que delas necessitava para se justificar, e do próprio Fordismo, cujo princípio da produção em massa necessita de vias para ser escoada.

Slavoj Žižek aponta a existência de três modalidades do Real: “o Real real, o Real simbólico e o Real imaginário, que ele define como aquele misterioso je ne sais quoi, a alguma coisa impenetrável, que por conta de sua dimensão sublime brilha através de um objeto ordinário" (2008, p.xii). É exatamente essa leitura que faço da entidade física "a estrada" no romance de McCarthy. Aqui, se transforma num personagem, e, de certa maneira, é o único presente ao longo de toda a narrativa, ao lado do Homem e do Menino, testemunha silenciosa e ameaçadora.

Tal qual esta, a outra presença constante no livro é a crise da linguagem. Na medida em que seres e objetos deixam de existir, seus nomes tendem a desaparecer também. "Linguagem também retornou aos seus rudimentos e agora precisa ser re-imaginada" (KUNSA, 2009, p.58). McCarthy sempre foi um escritor de um estilo perceptivel. Desde seu primeiro romance The Orchard Keeper (1965), ficou conhecido por uma prosa rebuscada, que encontra suas origens na literatura de William Faulkner e Herman Melville. Aqui, no entanto, o estilo está mais próximo de, digamos, Samuel Beckett ou Ernest Hemingway, como apontam alguns, com uma prosa precisa e direta, quase telegráfica, sem espaço para malabarismos literários. 
Outra constante em sua obra é a violência, que parece inerente do ser humano-ou como diz Timothy Parrish: "a brutal compreensão de McCarthy da história dos Estados Unidos num ciclo sem fim de violência" (2008, p.34). Em Blood Meridian, esta é triunfante, como em nenhuma outra obra do escritor. O romance lida com um grupo de mercenários que caçam índios para os escalpelarem.

Em The Road, porém, há outro elemento raro na obra do escritor: redenção e graça, que, embora presente em algumas histórias anteriores do escritor, nunca foram tão claras como aqui. Em Outer dark (1968), o segundo romance de McCarthy, uma jovem mãe busca o seu recém-nascido, filho de um incesto com seu irmão, que, aliás, roubou-lhe o bebê assim que este nasceu e o deixou sozinho num bosque. A personagem feminina chega bem perto dessa redenção - mesmo que nem tenha ciência disso em alguns momentos - mas jamais conseguira encontrar seu filho, vítima de um derramamento de sangue que beira o pósapocalipse, ao final do romance.

E quando o autor não encontra uma forma condizente com o conteúdo, ele tende a adaptar. McCarthy nada mais faz que adequar o que o romance tem a oferecer. $\mathrm{O}$ momento da gestação de The Road era um de crise - que até hoje não passou - e assim, surge uma tensão entre forma e conteúdo. O livro inteiro é um campo de batalha onde os dois aspectos duelam. O ruído, o dado problemático, então, é seu final, que soa abrupto quando a nova família-feliz aparece sem qualquer prenúncio. É o autor se curvando às obrigatoriedades da forma.

Aqui, a matéria histórica irá ganhar força a partir do momento no qual deixa de ser necessária a busca por uma nova forma, 
uma vez que aquela é a retomada do mesmo de sempre. Não há falência na forma aqui - pelo contrário, na conclusão conservadora e retrógrada, McCarthy reafirma o romance como a forma hegemônica de nosso tempo, uma vez que nenhum dos dois estão comportando qualquer tipo de revolução.

Pai e filho se intitulam os caras bons (the good guys, no original), e carregam a chama (carry the fire). São esses dois elementos que servem de força motriz para o menino seguir em frente - uma vez que, para ele, se quer há a figuração de um mundo melhor, coisa que ele desconhece. Esse status de heróis do romance deriva da recusa dos protagonistas de se alimentarem de pessoas ou cachorros - ao contrário dos canibais, a causa, aliás, do suicídio da mãe, com medo de ser capturada por essas gangues. O Homem carrega uma pistola com duas balas, uma para ele, outra para o filho, caso seja necessário.

No entanto, o Pai andando nesse mundo apocalíptico, vivendo sem regras, e buscando justificativa na redenção para tudo o que comete, é, em última instância, reflexo da quebra do Contrato Social, ou seja, um retorno a um estado de natureza:

O final apocalíptico destrói toda a aparência de uma vida política organizada, portanto produzindo condições para o estado de natureza. Mas para que o contrato social emerja do pós-apocalíptico é preciso haver alguma consideração que a vida pode continuar. (CURTIS, 2012, p.18)

Seria assim, então, justificável qualquer medida nesse hiato do Contrato Social para a sobrevivência? Do ponto de vista do Pai, sim. Sua mulher, a mãe do garoto, parece ter previsto esse estado 
primitivo, e antes que fosse capturada se entregou a uma espécie de sacrifício em vão.

Apesar de serem os "caras bons" confessos do romance, há uma tensão ética e moral entre pai e filho. O garoto é "mais bom" do que o pai, que não está disposto a ceder a nenhuma pessoa. Num episódio, após serem atacados por um ladrão, o pai consegue recuperar os seus pertences, mas, para desespero do garoto, deixa o assaltante completamente nu, sem qualquer possibilidade de sobrevivência no frio que os cerca:

Ele [o pai] puxou o carrinho e o girou e colocou a pistola na parte superior e olhou para o garoto. Vamos, ele disse. E eles se dirigiram pela estrada rumo ao sul com o garoto chorando e olhando para trás para a criatura nua e magricela parada lá na estrada tremendo e se apertando. Oh Papa, ele chorou.

Pare.

Não consigo parar.

O que você acha que aconteceria conosco se não tivéssemos o alcançado? Pare.

Estou tentando. (MCCARTHY, 2006, p.258)

Se até então li o romance na versão mais corrente de sua interpretação, como uma história pós-apocalíptica, gostaria de propor uma outra compreensão, que não toma como um fato certo o fim do mundo. Eric Cazdyn faz uma diferenciação entre crise e desastre que é bastante elucidativa aqui. Crise:

definida pela sua curta duração - requerendo decisões imediatas, sem possibilidades de concessão, evasão ou repressão. Uma crise 
significa que podemos, talvez, suspender nossas regras comuns e padrões éticos porque precisamos "agir agora!" $(2012$, p.3)

O desastre, por sua vez, segundo o autor:

é o momento quando a configuração sustentável das relações fracassa, quando as relações entre uma coisa e outra deteriora. [...] Em filosofia, desastre é aquele momento quando pensar está interrompida da história, enquanto indivíduos estão em um infortúnio psicológico, quando eles não são mais capazes de se relacionar com o mundo. (CAZDYN, 2012, p.55)

A crise, ao contrário do desastre, é algo necessário para o capitalismo, é a forma como ele se recicla, se reinventa. "Sistemas são estruturados de forma que crises acontecerão para os fortalecer e os reproduzir" (CAZDYN, 2012, p.54). Diante dos comportamentos do Homem e do Garoto, é possível pensar que eles têm visões opostas em relação ao que causou tanto estrago no planeta. 0 menino, desconhecendo o mundo antes de ser como é descrito no romance, encara o cataclismo como um desastre, algo irreversível, e que é preciso saber sobreviver sem chances de mudança.

Seu pai, por outro lado, encara apenas como uma crise, e, dessa forma, existe a possibilidade de que o mundo se transforme - não necessariamente volte a ser como era, tal coisa parece impossível, mas também ele não parece crer que viverá para sempre num mundo coberto de cinzas. A prova mais crucial disso é a forma como ele suspende as regras e os padrões éticos porque precisa agir agora.

Além disso, se seguirmos a lógica de Cazdyn, há um elemento ausente em The Road: a revolução. Essa é "um momento quando um 
novo conjunto de relações tomam posse com um sistema diferente" (CAZDYN, 2012, p.54). Embora tentador, não se pode inferir que, ao final, haja qualquer espécie de grande transformação. Quando Garoto, agora órfão, pois seu pai morreu algumas páginas atrás, é recebido por uma família nuclear, a impressão é a da manutenção ou, quando muito, da reforma da sociedade e do sistema anterior ao cataclismo.

O Pós-Apocalipse seria o momento após um desastre para acabar com toda e qualquer possibilidade de outros desastres. A ativista e jornalista Naomi Klein, em seu The Shock Doctrine, relembra as origens bíblicas deste, e relaciona tal estado aos ideólogos do livre mercado que são interessados em crises e desastres. "Realidade não-apocalípticas simplesmente não são acolhedoras às ambições deles" (KLEIN, 2007, p.25).

Žižek define o 11 de setembro como o momento que concluiu o século XX e deu início ao XXI (2002, p.5). Os ataques, para o filósofo, fizeram o mundo ocidental (especialmente os americanos, é claro) acordar da realidade material naquilo que ele chama de "deserto do real". Uma das narrativas nacionais a ganhar nos EUA naquele momento foi a do patriotismo - "a inocência sob ameaça, a onda de orgulho patriótico" (ŽIŽEK, 2002, p.51). Em The Road, tal narrativa não é facilmente identificada - se é que ela se materializa no romance.

Porém, se tomarmos a inocência do garoto, que já nasceu no mundo devastado, como a inocência americana, Žižek nos teria muito a dizer sobre esta, pois, para ele, "não há nada de 'inocente' em redescobrir a inocência americana, em se livrar do sentido de culpa histórica ou ironia, que impediu muitos americanos de assumir completamente sua identidade nacional" (ŽIŽEK, 2002, p.45). 
Mas, então, no contexto do romance, como inserir a identidade americana no mundo global? É uma questão delicada, pois, em The Road não há a ideia de países, é como se a globalização tivesse, de uma vez por todas, esmaecido as fronteiras. É como se finalmente o mundo todo vivesse de acordo com um único modelo. Ora, a globalização, grosso modo, nada mais é do que isso. Da mesma forma, classes sociais não existem mais nesse mundo de crise do romance. As categorias que dividem os humanos são suas aptidões para a sobrevivência.

As formulações de Cazdyn sobre a globalização estranhamente permitem um paralelo entre esta e o mundo devastado de The Road:

[Imaginar] o que está além da globalização é como imaginar o que vem antes e depois dos tempos - um desafio mental, na verdade. Mas essa inabilidade de pensar além da globalização é precisamente uma das ideologias mais cruciais da globalização. Se formos imaginar o que aconteceria depois da globalização, a globalização deixaria de existir, pois globalização é exatamente a categoria que incorpora e absorve tudo em seu domínio, especialmente a própria ideia de seu próprio fim. (2012, p.16)

Seria The Road então um romance sobre o fim da globalização ou estaria a globalização disfarçada como o fim do mundo? Como dizem alguns teóricos - e Cazdyn cita essa frase em um certo momento em The Already Dead - é mais fácil imaginar o fim do mundo do que o fim do capitalismo. Ele lembra que a crise de 2008 foi um momento em quando o fim do capitalismo parecia algo possível, e isso não acontecia desde o crash de 1929 (CAZDYN, 2012, p.61). No entanto, o capitalismo vive exatamente dessas crises; elas 
são inerentes ao sistema. E o final do romance de McCarthy pode apontar o fim da crise.

Para Jameson, "todos romances são históricos, [dessa forma,] o romance do presente se tornou tão contraditório quanto o romance histórico". Ou, ainda, "a crise formal do romance origina na situação histórica, que parece muito complexa para apresentação num modelo narrativo" (1974, p.350). The Road se materializa exatamente no centro dessa crise, portanto, como construir um romance sobre um mundo que está se dissolvendo? Nesse sentindo, esse é um romance histórico num momento de crise da história. E isso implicaria numa crise no gênero? Se fizermos essa leitura - na ótica de Jameson, não há como fugir - o fim do mundo é um evento histórico.

E quem seriam esses protagonistas sobreviventes ao fim do mundo? Conseguiriam eles recriar a civilização? Seguir em frente? Para responder a essas perguntas, recorro novamente Cazdyn numa formulação interessante sobre nossa condição contemporânea. Para ele, "é tão impossível imaginar os Estados Unidos pós-global quanto é imaginar um futuro que não é uma extensão crônica do presente" (2012, p.8). A morte, no entanto, é a forma pura de mudança radical. Porém, quando ela nos é negada, nos transformamos em "crônicos" - ou seja, seres eternamente presos a uma condição, impossibilitados de mudança.

Uma vez que o futuro não está desvinculado do capitalismo, aos personagens (e a nós também, por que não?) só restam duas opções: a morte ou o estado crônico. A morte não é necessariamente a morte per se. $\mathrm{O}$ conceito de already dead ${ }^{2}$ implica em repensar a 2 Ao pé da letra seriam os 'já-mortos', ou, de maneira adaptada, 'os mortos vivos', o que poderia gerar confusão com os zumbis, uma terceira categoria especificada por Cazdyn. Para evita-la, optei por manter o termo no original. 
relação entre morte e vida, e aquele que está morto, mas ainda tem de morrer. Ou, indo além:

Por meio de intervenções interiormente impensáveis no contexto do capitalismo global que produz uma temporalidade alternativa, o already-dead vive uma vida impossível dentro de uma morte inescapável. Entre toda a miséria, esse espaço impossível também equivale a uma zona livre na qual o already dead pode transgredir os limites estruturais da situação presente. (CAZDYN, 2012, p.194)

Esse é um retrato da figura paterna do romance. Ciente de sua morte, procura condições para que o filho possa sobreviver sem ele. Essa ideia reforça também o ponto de vista que ele e o garoto têm do cataclismo. Sendo apenas uma crise, seu filho poderá continuar vivo quando esta acabar, o que, coloca o garoto na condição daquele que Cazdyn chama de new chronic, para quem tudo sempre continuará o mesmo, ao que o crítico chama de "subsequentes agoras" (CAZDYN, 2012, p.17).

Para o Garoto, o novo agora, ao final de The Road é encontrar essa nova família. Depois de se despedir do corpo do pai, a quem faz a promessa de conversar com ele todos os dias, é recebido de forma definitiva por sua nova mãe que o abraça, e se diz feliz por o receber, e fala para ele sobre Deus. O garoto, diz o narrador, "tentou conversar com Deus, mas a melhor coisa era falar com seu pai" (MCCARTHY, 2006, p.286). Depois dessa cena, uma espécie de coda fala de trutas nos rios das montanhas, seu cheiro de musgo, e que o padrão de suas escamas formava 'mapas do mundo em sua transformação. Mapas e labirintos' (MCCARTHY, 2006, p.288). 
Ao fim dos romances, conforme explica Jameson, há uma espécie de contradição: para que a narrativa projete um sentido de totalidade da experiência no tempo e espaço é preciso chegar a um encerramento. Esse, no entanto, é a marca do limite além do qual o pensamento não pode ir (2007, p.283). Em The Road, creio, essa contradição se materializa em duas formas. A primeira se dá com a morte do pai - ou melhor reformulando, quando ele deixa de existir fisicamente para o filho, ou seja, quando o garoto precisa abandonar o corpo do homem, e seguir em frente com sua nova família. Não há interesse para o romance, o acompanhar nessa nova trajetória.

A segunda, por sua vez, tem a ver com a estrutura do romance, mas não deixa de estar ligada a anterior. Se, com o que falamos até aqui, tomarmos o pai como o focalizador do romance, a história é contada a partir de seu ponto de vista - vide as diferenças acima citadas entre a visão do pai e do filho -, pois este prevalece, não há mais como contar a história a partir do momento em que ele sai de cena.

E, por fim, os mapas e labirintos das escamas das trutas são os mesmos que compõem a narrativa de The Road, cujo mapeamento serve para iluminar sua complexidade - reflexo da nossa pós-modernidade.

\section{REFERÊNCIAS}

BERGER, James. (2003). “There's No Backhand to This. In: GREENBERG, Judith (ed.). Trauma At Home - After 9/11. Lincoln \& London: University of Nebraska Press.

CAZDYN, Eric. (2012). The Already Dead. Durham: Duke University Press.

CURTIS, Claire P. (2012). "Last One Out, Please Turn Out the Lights". In:

Postapocalyptic Fiction and the End of Social Contract. Lanham: Lexington Books. 
FRYE, Steven. (2013). "Histories, Novels, Ideas: Cormac McCarthy and the art of Philosphy". In: The Cambridge Companion to Cormac McCarthy. New York: Cambrigde University Press.

. (2011). Understanding Cormac McCarthy. Columbia: The University of South Carolina Press.

GRAY, Richard. (2011). After the Fall - American Literature since 9/11. Malden \& Oxford: Wiley-Blackwell.

GREENBERG, Judith, (2003). “Wounded New York”. In: GREENBERG, Judith (ed.). Trauma At Home - After 9/11. Lincoln \& London: University of Nebraska Press.

HARDT, Michael; WEEKS, Kathi (ed.). The Jameson Reader. Oxford \& Massachusetts: Blackwell Publishers.

JAMESON, Fredric. (1974). Marxism and Form. Princeton: Princeton University Press.

. (2000). “Cognitive Mapping”. In: HARDT, Michael; WEEKS, Kathi (ed.). The Jameson Reader. Oxford \& Massachusetts: Blackwell Publishers.

. (1991). Postmodernism or The logic of Late Capitalism. Durham: Duke University Press.

. (2007). Archaeologies of the Future. London \& New York: Verso.

JURGENSEN, John. (2009). Hollywood's favorite cowboy. The Wall Street Journal. New York, 20 November 2009. In http://online.wsj.com/article/SB10001424052 748704576204574529703577274572.html. Acesso em 20.jul.2016.

KENNEDY, William. (2006). Left Behind. The New York Times, 8 Outubro 2006. In http://www.nytimes.com/2006/10/08/books/review/Kennedy.t.html. Acesso em 20.jul.2016.

KLEIN, Naomi. (2007). The Shock Doctrine. New York: Picador.

KUNSA, Ashley. (2009). "Maps of the world in its becoming: Post-Apocalyptic Naming in Cormac McCarthy's The Road". In: Journal of Modern Literature 33.1. LUKÁCS, Georg. (1971). The theory of the Novel. Tradução de Ann Bostock, Massachussets: The MIS Press.

MCCARTHY, Cormac. (2006). The Road. New York: Vintage International. . (1993). Outer Dark. New York: Vintage International. 
PARRISH, Thimoty. (2008). From the Civil war to the Apocalypse. Amherst: University of Massachusetts Press.

SHEEHAN, Paul. (2012). "Road, fires, trees: Cormac McCarthy's Post-America". In: MURPHET, Julian; STEVEN, Mark. Styles of Extinction - Cormac McCarthy's The Road. London \& New York: Continuum.

ŽIžEK, Slavoj. (2008). For they know not what they do. London \& New York: Verso. . (2002). Welcome to the desert of the real - Five Essays on September 11 and related dates. London and New York: Verso. 